\title{
ORIGINAL RESEARCH \\ Uses of crude oil as traditional medicine: a survey of mothers in a rural clinic in South-south Nigeria
}

\author{
PO Dienye, AB Akani, K Itimi \\ Department of Family Medicine, University of Port Harcourt Teaching Hospital, Port Harcourt, \\ Nigeria.
}

Submitted: 12 July 2011; Revised: 23 January 2012; Published: 12 July 2012

Dienye PO, Akani AB, Itimi K

Uses of crude oil as traditional medicine: a survey of mothers in a rural clinic in South-south Nigeria Rural and Remote Health 12: 1858. (Online) 2012

Available: http://www.rrh.org.au

A B S T R A C T

Introduction: Crude oil is used as traditional medicine among rural dwellers in South-south Nigeria. Although complications have been reported following its use, this rural populace holds tenaciously to an erroneous belief in its efficacy in treating many ailments. Despite this widespread use there are no known studies from the region on the use of crude oil in this way. This study surveyed the use of crude oil by rural mothers with the objectives of determining the proportion of mothers who use crude oil as traditional medicine, the reasons for its use, the diseases believed to be cured by it, and to establish the identity of those who administer crude oil.

Method: This cross-sectional study was conducted in Bethesda Clinic Ngo in South- south Nigeria in the period January-December 2009.

Results: Of 420 mothers recruited, 134 (31.9\%) used crude oil as medication. Their ages ranged from 19 to 47 years with a mean of $33.72 \pm 9.45$ years. Mothers older than 30 years were significantly more likely to use crude oil than those younger than 30 years $(\chi 2=4.56, p=0.033, \mathrm{RR}=0.737, \mathrm{CI}=0.548-0.990)$. There was no statistically significant association between marital status and the use of crude oil as traditional medicine $(\chi 2=1.24, p=0.265, \mathrm{RR}=0.793, \mathrm{CI}=0.545-1.255)$. Although the majority of participants $(78.86 \%)$ had a minimum of primary education level (educated group), the uneducated participants were significantly more likely to use crude oil $(\chi 2=62.67, p<0.001, \mathrm{RR}=2.936, \mathrm{CI}=2.243-3.776)$. The proportion of mothers using crude oil was significantly higher among those whose occupation was fishing $(\chi 2=10.98, p=0.001, \mathrm{RR}=1.629$, CI $=1.198-2.232)$. The most common use of crude oil was for febrile convulsions (82.1\%). The reasons for using crude oil were that crude oil was 
inexpensive (66.4\%) and that available hospitals were costly and/or inefficient (61.9\%). The most common administrators of crude oil were neighbours $(73.2 \%)$.

Conclusion: A high proportion of mothers attending Bethesda Clinic Ngo use crude oil on their children as a traditional medicine, and this is because of their belief in its effectiveness, and its availability and affordability. The use of this product is encouraged the country's costly and inefficient health system. Neighbours play a large role in the administration of crude oil and this is consistent with the local culture.

Key words: crude oil, South-south Nigeria, traditional medicine.

\section{Introduction}

The use of traditional medicine (TM) is widespread in developing countries ${ }^{1}$. In Africa rural and urban dwellers often supplement the treatment of orthodox medical practitioners with treatment from traditional healers ${ }^{2}$. In 2002 WHO estimated that TM provided $80 \%-90 \%$ of healthcare in Africa ${ }^{1}$, and this is supported by findings that in Ghana, Mali, Nigeria and Zambia, the first-line treatment for $60 \%$ of children with high fever from malaria was herbal medicines at home ${ }^{3}$.

Among Nigerians, there are powerful cultural and religious beliefs and practices relating to health. Approximately $85 \%$ of the population use TM and consult TM practitioners for health care ${ }^{4}$. Nigeria's $70 \%$ rural population ${ }^{5}$ relies almost exclusively on TM for their healthcare needs ${ }^{6}$, and this has been attributed to poverty ${ }^{4}$, low or no access to quality orthodox medicine, illiteracy and ignorance ${ }^{7}$.

In the Niger Delta region of South-south Nigeria, crude oil is found in great quantities; however, years of oil exploration with frequent spillages have led to severe environmental degradation with the destruction of farmlands, and aquatic flora and fauna. The local fishing industry has been severely affected leading to poverty and its associated problems among the rural population. The 'oil boom' has become 'oil doom', and today life in the rural Niger Delta region is one of hunger, poverty and injustice ${ }^{4}$. Due to the prevalence of poverty in this rural area, many individuals rely on TM and/or self-medication with orthodox drugs when they are ill. Where self-treatment is unsuccessful, patients must pay for expensive services from private practitioners and pharmacists $^{5,6}$ because the government health services are inadequate and ineffective.

Crude oil, the source of such misery to many, one TM used by the Niger Delta population. Due to the continual spillages, crude oil is easy to access, and a belief that 'everything under the earth has medicinal use' has meant it is highly regarded locally as a remedy for a variety of ailments, including gastrointestinal disorders, burns, 'foot rot' and leg ulcers, and poisoning; it is also used in witchcraft ${ }^{8}$. The oil is applied to the skin, mixed with alcohol or water as a drink, and instilled into body orifices such as nostrils, ears, anus, vagina and urethra.

The use of crude oil as TM in Nigeria has been reported for an analgesic effect comparable to aspirin ${ }^{8}$. Its use and complications has been reported in children with febrile convulsions ${ }^{9}$. Complications from its use have been reported to affect a variety of organs, such as the skin, lungs, liver and kidneys ${ }^{10}$. Skin exposure may result in the formation of vesicles, blisters and even extensive epidermolysis ${ }^{10}$. Its ingestion may result in nausea, vomiting and diarrhoea, and the aspiration of crude oil during vomiting results in chemical pneumonitis $^{11}$. Central nervous system symptoms range from vertigo and headache from the ingestion of small doses, to lethargy, convulsions, coma and death with larger doses. Renal failure has been described as another toxic effect ${ }^{12}$. Despite these complications, the rural populace holds tenaciously to a belief in the efficacy of crude oil for the treatment of a wide range of ailments. 
There is no known study conducted into this use of crude oil in Ngo, a rural Niger Delta community in South-south Nigeria; therefore, the present study aimed to survey the use of crude oil by rural mothers with the objectives of determining the proportion of mothers who use crude oil as $\mathrm{TM}$, the reasons for its use, the diseases believed to be cured by it and to discover who administers crude oil.

\section{Setting}

This study was conducted between January and December 2009 in Bethesda Clinic Ngo, a rural Niger Delta town in South-south Nigeria. To reach Ngo from Port Harcourt (the capital of Rivers State of Nigeria), it is necessary to travel 1.5 hours by boat or to make a longer journey by road that is followed by a $30 \mathrm{~min}$ boat trip. The town lacks the basic amenities of electricity, pipe-borne water and functional government-owned health facilities (the only government health facility is a poorly equipped primary health centre managed by the local government authority). There are also few shops where medicine can be purchased. Ngo town has a population of approximately 10000 people, whose major occupation is fishing. The fishing industry has been severely adversely affected by years of environmental degradation associated with oil exploration and spillages, resulting in a very high level of poverty in the area ${ }^{13}$. The major religion is Christianity.

Bethesda Clinic is the only private clinic in the locality. It has a full primary-care medical staff. The service is primary-care oriented general practice and therefore a wide range of patients attend (surgical, medical, gynaecological and paediatric). The clinic is attended by locals from Ngo and people from neighbouring fishing communities located on small islands. Transport from the islands to Ngo is mainly by hand-pulled canoes, which is slow and difficult. Bethesda clinic occasionally allows part-payment of hospital bills if the patients are identified by a responsible member of the community. This enables occasional use of the facility despite financial hardship.

\section{Methods}

\section{Study design, sample size and power analysis}

A cross-sectional study design was used to detect a 5\% difference in the prevalence of use of crude oil, with an a error of $5 \%$, acceptable b error of $20 \%$ (statistical power of $80 \%$ ). Because there was no known prevalence study in the study environment, a prevalence of $50 \%$ was adopted. Using the usual formula for sample size determination for studying proportions in populations of more than $10000^{14}$, the determined minimum sample size was 420 .

\section{Subjects}

The study population consisted of a consecutive sample of mothers who presented to the clinic with sick children. Mothers were chosen because tradition dictates it is their responsibility to care for members of the family who are unwell, especially children. They are therefore more likely to use available medications on family members.

Inclusion criteria: Mothers who gave their consent to participate in the study.

Exclusion criteria: Mothers in the following categories were excluded:

- those who did not give their consent to participate in the study

- those who were very sick themselves

- $\quad$ those whose children were very sick (because it was not possible to administer the questionnaire).

\section{Procedure}

This study commenced with informal conversations with mothers attending the clinic about medicinal use of crude oil in their communities. A structured questionnaire was designed on the basis of information provided and pre-tested on 40 mothers; ambiguities were then corrected. 
The instrument contained straight dichotomous questions and close-ended questions. It was administered to consenting mothers by two nurses (trained for a period of 1 week) and required approximately $10 \mathrm{~min}$ to complete. The information sought concerned participants' utilization of crude oil and socio-demographic characteristics such as age, marital status, level of education and occupation. Those identified as crude oil users were asked about the diseases 'treated' with crude oil, their reasons for using crude oil as treatment and the identity of the administrators of crude oil. Confidentiality was assured.

The data obtained were crossed-checked by the researchers to assure correct data entry and analyzed using SPSS v15 (www.spss.com). For the purpose of this study, age groups, educational status and occupational groups were collapsed into dichotomous measures to facilitate statistical calculations. The age groups were dichotomized according to the year free primary education commenced (1979) and grouped into those aged 30 years and older, and those younger than 30 years. Educational status was grouped as uneducated or educated (primary to tertiary level), and occupation groups fishing and others (traders, civil servants and unemployed). Frequency tables were constructed, percentages, $\chi 2$ and relative risk (RR) were calculated. Statistical significance was set at $95 \%$ confidence level or at $p$-value $\leq 0.05$.

\section{Ethics approval}

Permission to conduct the study was obtained from the management of Bethesda Clinic Ngo, Nigeria. Approval for this study was obtained from the Ethical Committee of the Rivers State Ministry of Health, Port Harcourt (\#MH/PHC/41/T/10) before the study's commencement.

\section{Results}

Of the 420 mothers recruited, 134 (31.9\%) used crude oil as medication. Their ages ranged from 19 to 47 years with a mean age of $33.72 \pm 9.45$ years. Most of the users of crude oil $(55.22 \%)$ were older than 30 years of age. Mothers older than 30 years were significantly more likely to use crude oil than those younger than 30 years $(\chi 2=4.56, p=0.033, \mathrm{RR}=0.737, \mathrm{CI}=$ 0.548-0.990). Among the crude oil users, $86.57 \%$ were married and there was no statistically significant association between marital status and the use of crude oil as TM $(\chi 2=1.24, p=$ $0.265, \mathrm{RR}=0.793, \mathrm{CI}=0.545-1.255)$. Although the majority of participants $(78.86 \%)$ had a minimum of primary education level (educated), the uneducated participants were significantly more likely to use crude oil $(\chi 2=62.67, p<0.001, \mathrm{RR}=2.936, \mathrm{CI}=$ 2.243-3.776). The occupation of most mothers was fishing and the proportion of mothers using crude oil was significantly higher in this occupational group $(\chi 2=10.98, p=0.001, \mathrm{RR}=1.629$, $\mathrm{CI}=1.198-2.232)$. There was a significantly higher number of uneducated mothers older than 30 years $(p<0.001, \mathrm{RR}=1.47$ and 95\% CI $=1.297-1.643$; Table 2).

The most prevalent use of crude oil was for febrile convulsions (82.1\%), followed by gastrointestinal disorders (63.4\%) and poisoning (54.5\%). Participants' reasons for using crude oil were that crude oil was inexpensive (66.4\%) and the available hospitals were costly or inefficient (61.9\%). The administrators of crude oil were most often neighbours (73.2\%).

\section{Discussion}

In this survey $31.9 \%$ of mothers were found to use crude oil as TM. Discussion of this finding is constrained by the absence of previous surveys on the use of crude oil for therapeutic. The rural nature of Ngo town imposes both geographic and economic barriers to accessing efficient healthcare services which are mainly concentrated in urban Nigeria, privately owned and profit oriented, placing their use out of reach of the average rural household. More affordable government health facilities in the locality are not attractive because of their inadequate supply of drugs and personnel. Rural people therefore use available TM unless the situation becomes critical ${ }^{7}$. The use of crude oil as TM in this locality is further encouraged by the proliferation of 'prayer houses' where spiritual healers prescribe plant, animal and mineral products as pharmacologic adjuncts to their spiritual therapy for various diseases. 
Table 1: Sociodemographic characteristics of mothers

\begin{tabular}{|c|c|c|c|c|c|c|c|}
\hline \multirow[t]{2}{*}{ Characteristics } & \multicolumn{2}{|c|}{ Crude oil (\%) } & \multirow{2}{*}{$\begin{array}{l}\text { Total (\%) } \\
(n=420)\end{array}$} & \multicolumn{4}{|c|}{ Statistic } \\
\hline & $\begin{array}{c}+ \\
(n=134)\end{array}$ & $\begin{array}{c}- \\
(n=286)\end{array}$ & & $\chi^{2}$ & p-value & $\mathbf{R R}$ & CI \\
\hline \multicolumn{8}{|l|}{ Age in years } \\
\hline$\leq 30$ & $60(44.78)$ & $160(55.94)$ & $220(52.38)$ & 4.56 & 0.033 & 0.737 & $0.548-0.990$ \\
\hline$>30$ & $74(55.22)$ & $126(44.06)$ & $200(47.62)$ & & & & \\
\hline \multicolumn{8}{|l|}{ Marital status } \\
\hline Married & $116(86.57)$ & $258(90.21)$ & $374(89.05)$ & 1.24 & 0.265 & 0.793 & $0.545-1.255$ \\
\hline Not married & $18(13.43)$ & $28(9.79)$ & $46(10.95)$ & & & & \\
\hline \multicolumn{8}{|l|}{ Education status } \\
\hline Uneducated & $70(52.24)$ & $44(15.38)$ & $114(21.14)$ & 62.67 & $<0.001$ & 2.936 & $2.243-3.776$ \\
\hline Educated & $64(47.76)$ & $242(84.62)$ & $306(78.86)$ & & & & \\
\hline \multicolumn{8}{|l|}{ Occupation } \\
\hline Fishing & $86(64.18)$ & $134(46.85)$ & $220(52.38)$ & 10.98 & 0.001 & 1.629 & $1.198-2.232$ \\
\hline Others & $48(35.82)$ & $152(53.15)$ & $200(47.62)$ & & & & \\
\hline
\end{tabular}

Table 2: Association between mothers' age and educational status

\begin{tabular}{|c|c|c|c|c|c|c|c|}
\hline \multirow{2}{*}{$\begin{array}{c}\text { Age } \\
\text { (years) }\end{array}$} & \multicolumn{2}{|c|}{ Education status (\%) } & \multirow{2}{*}{ Total } & \multicolumn{4}{|c|}{ Statistics } \\
\cline { 2 - 3 } & Educated & Uneducated & & $\boldsymbol{\chi}^{\mathbf{2}}$ & $\boldsymbol{p}^{\text {-value }}$ & $\mathbf{R R}$ & CI \\
\hline$\leq 30$ & $189(61.76)$ & $31(27.19)$ & 220 & 39.80 & $<0.001$ & 1.47 & $1.297-1.643$ \\
\hline$>30$ & $117(38.24)$ & $83(72.81)$ & 200 & & & & \\
\hline Total & 306 & 114 & 420 & & & & \\
\hline
\end{tabular}

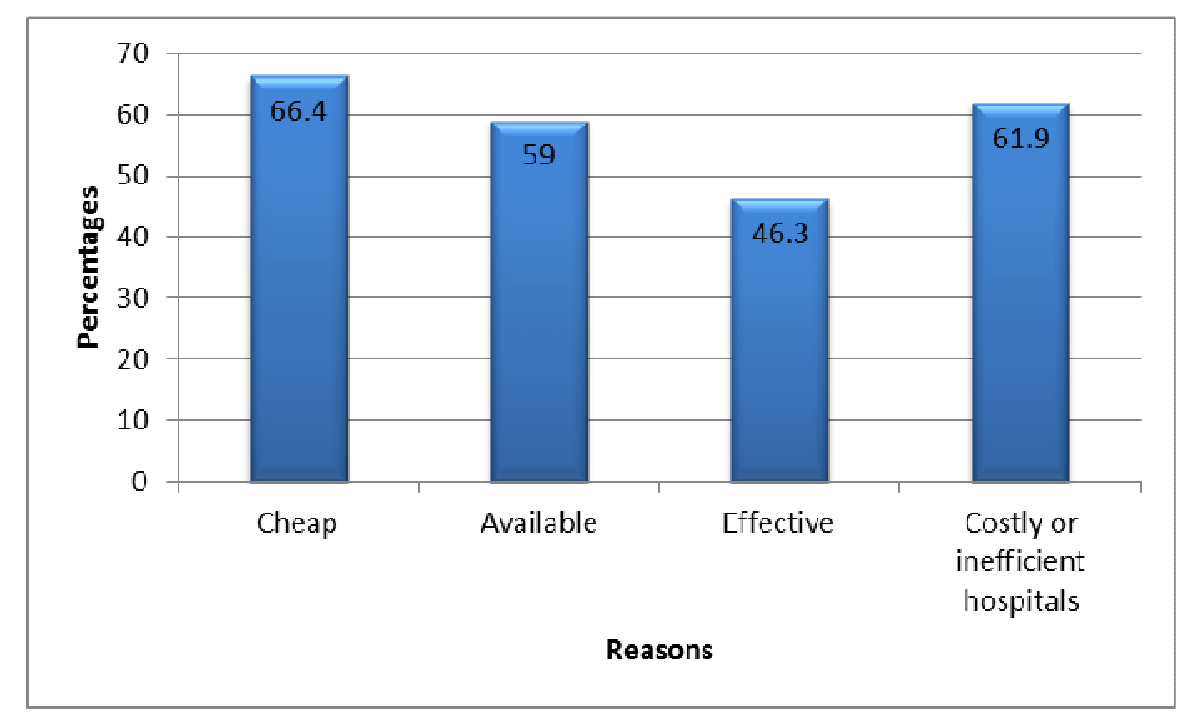

Figure 1: Reasons for using crude oil in treatment. 


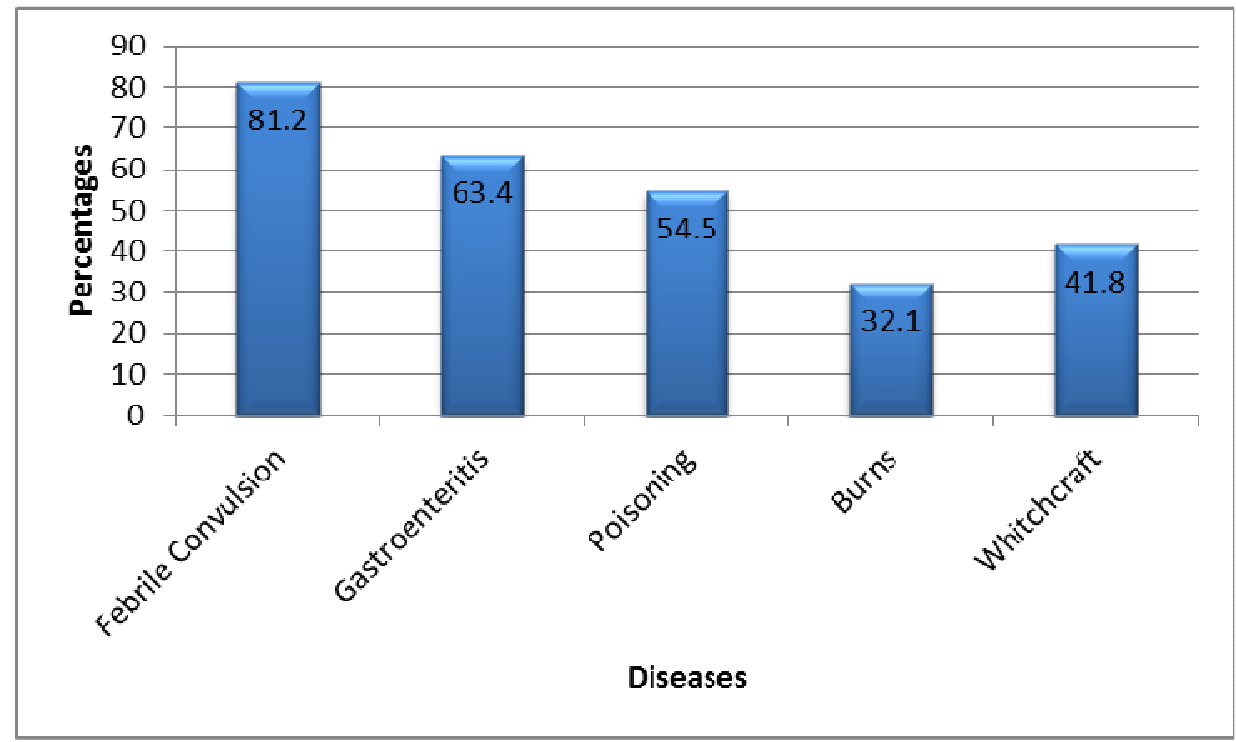

Figure 2: Mothers' knowledge of diseases treated with crude oil.

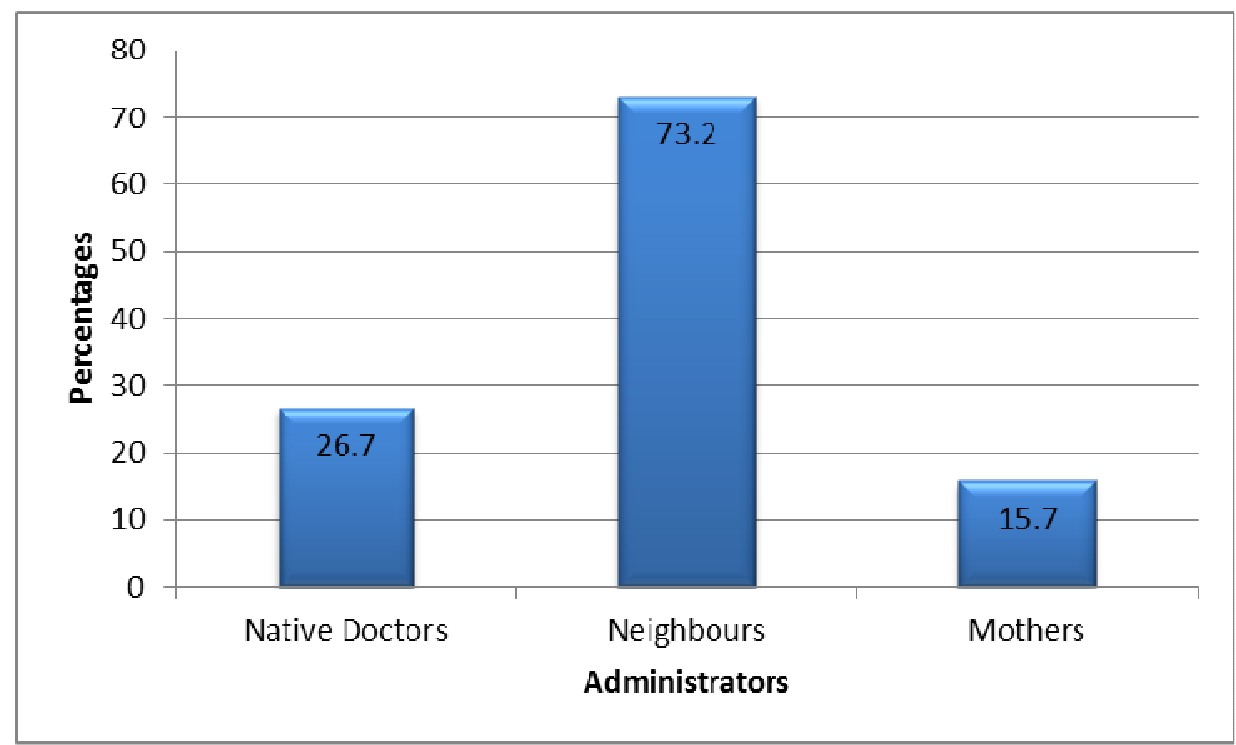

Figure 3: Administrators of crude oil.

Most of the study participants who used crude oil as TM were older than 30 years, married, uneducated and of fishing occupation, being of similar in age to TM users in South Africa (25-49 years) $)^{15}$. The younger mothers $(<30$ years) in this study who reported low usage of crude oil were the beneficiaries of free primary education which commenced in
1979 in most Nigerian states. The mothers older than 30 years were not exposed to the basic health education taught in primary schools.

Although there was not a statistically significant association between marital status and the use of crude oil, the single 
mothers were found to be more likely to use crude oil as TM. The married-to-single ratio in this study was distorted by the recruitment of mothers who brought their children to the clinic for treatment. To avoid discrimination, single attendees with sick children may claim to be married, thereby artificially reducing the single mothers' population. Single mothers are twice as likely as their married counterparts to experience financial hardship ${ }^{16}$ and are therefore more likely to use the most affordable medications available in times of need.

The greater use of TM by uneducated mothers in this study is similar to the findings of a study of pregnant women in a tertiary hospital in Northern Nigeria ${ }^{17}$. It is, however, contrary to the findings on TM use among pregnant Australian women where this was more common among women with higher education levels ${ }^{18}$. In the locality of the present study, access to TM is not restricted, leading to indiscriminate use that is encouraged by the usually untested therapeutic claims of the popular traditional healers who also live in these communities. High rates of illiteracy and poverty in this rural population mean that people are vulnerable to the claims of these vendors and often unable to afford orthodox medications as an alternative ${ }^{17}$.

The high use of crude oil among women whose occupation was fishing is related to the destruction of aquatic life from recurring oil spillages and subsequent collapse of their livelihood. Because the cost of modern medicine is too high for them they use what is available and affordable. Government and oil company action is urgently needed improve the financial situation of these rural dwellers.

The list of diseases given by the mothers in the present survey is in agreement with other Nigerian studies ${ }^{8,9}$. Traditional medicine is seen as a unique therapeutic strategy, especially in the treatment of health dilemmas associated with witchcraft, evil force and poisoning. The popularity of crude oil to treat febrile convulsions could be attributed to the common belief that the disorder is the result of witchcraft and evil forces ${ }^{19}$.
The reasons given by participants for using crude oil as a medication (affordability, availability, efficacy and costly or inefficiency of orthodox medical facilities) are similar to the findings by Mafimisebi et $\mathrm{al}^{7}$, who provided the following additional reasons: inadequate modern medical practitioners, unfriendliness of hospital staff, poor communication (eg patients not being told the nature and causes of their illnesses), inadequate technical services leading to poor quality care, treatment that is divorced from the patient's culture, family and community, and the treatment only addressing biological aspects of the illness rather than also addressing spiritual aspects. Another author stated that mothers may use crude oil in desperation as first aid, especially where health clinics were long distances from their homes $^{19}$. In summary, care-seeking choices are often embedded in cultural beliefs about the origins of illness and influenced by past experiences of care, rumour, financial or material circumstances, and social networks ${ }^{20,21}$.

The finding that majority (73.2\%) of crude oil administrators were neighbours is similar to the observation from Malawi (non-TM practitioner $=72.6 \%, \mathrm{TM}$ practitioner $=$ $27.4 \%)^{22}$. The involvement of neighbours in this study could be attributed to the existing cultural bond where each individual is 'his brother's keeper'. A convulsing child is a frightening event and the mother may be too distressed to effectively manage the convulsive episode ${ }^{23}$. If a neighbour takes on this responsibility they can administer any medication they believe to be useful. Therefore, although the TM practitioner is the originator of crude oil for TM therapy, societal input plays a crucial role in the perpetuation of the practice. Every physician contact with a rural dweller should therefore be seen as an opportunity for health promotion and education, discouraging the use of crude oil as a medication.

Finally, the use of crude oil as TM by mothers in this locality will persist until the socioeconomic status of women is enhanced in line with the UN Millennium Development Goals. 


\section{Limitations}

The study findings may not be generalizable to mothers in all the communities in South-south Nigeria and mothers who do not attend Bethesda Clinic for treatment. In order to recruit an adequate sample within the planned study period, a nonprobability sampling technique was used. This could have introduced bias into the study. Respondents recall bias cannot be excluded. Potential social stigmatization could have motivated some respondents to conceal the fact that they use crude oil.

\section{Conclusion}

This study has shown that a high proportion of mothers attending Bethesda Clinic, Ngo, use crude oil as TM for their children. They do so because of a belief that it is effective, and because it is available, affordable and cheap. Non-TM practitioners, especially neighbours, play a large role in the administration of crude oil, and this is consistent with the rural culture. The use of this toxic TM is encouraged by the costly or inefficient Nigerian health system.

To reverse the situation, it is suggested that promotive and preventive health campaigns on the harmful effects of using crude oil as TM should be implemented in churches, and also available in market squares, primary health centres and other community venues. The Nigerian Government must enforce immediate and rapid clean-up operations during oil spillages so as to protect the environment and reduce the availability of crude oil for inappropriate use by local people. A more comprehensive community based study is recommended.

\section{Acknowledgment}

The authors acknowledge the excellent cooperation of the staff of the Bethesda Clinic, Ngo Andoni, Rivers State, Nigeria.

\section{References}

1. WHO. Traditional medicine strategy 2002-2005. Geneva, WHO, 2002.

2. Fasola TR. The impact of traditional medicine on the people and environment of Nigeria. In: MFA Ivbijaro, F Akintola, RU Okechukwu (Eds). Sustainable Environmental Management in Nigeria. Ibadan: Mattivi , 2006; 251-267.

3. Peltzer K. Utilization and Practice of Traditional/Complementary/Alternative Medicine (TM/CAM) in South Africa. African Journal of Traditional, Complementary and Alternative Medicine 2009; 6(2): 175-185.

4. Adesina SK. Traditional medical care in Nigeria. (Online) no date. Available: http://www.onlinenigeria.com/links/LinksReadPrint. asp?blurb=574 (Accessed 28 September 2011).

5. Momodu MO. Information needs and information seeking behaviour of rural dwellers in Nigeria: a case study of Ekpoma in Esan West local government area of Edo State, Nigeria. Library Review 2002; 51(8): 406-410.

6. Olusegun T. Maternal Mortality, a Rural Community's Example. (Online) 2009. Available: http://ipsnews.net/news.asp?idnews $=48305$ (Accessed 28 September 2011).

7. Mafimisebi TE, Oguntade AE. Preparation and use of plant medicines for farmers' health in Southwest Nigeria: socio-cultural, magico-religious and economic aspects. Journal of Ethnobiology and Ethnomedicine 2010; 6:1. DOI:10.1186/1746-4269-6-1.

8. Orisakwe OE, Akumka DD, Afonne OJ, Gamanniel KS. Investigation into the pharmacological basis for some of the folkloric uses of Bonny light crude oil in Nigeria. Indian Journal of Pharmacology 2000; 32: 231-234. 
9. Otaigbe B.E. and Adesina A.F. Crude Oil Poisoning in a 2 Year Old Nigerian - A Case Report. Anil Aggrawal's Internet Journal of Forensic Medicine and Toxicology. (Online) 2005; 6(2): Available: http://www.anilaggrawal.com/ij/vol_006_no_002/papers/paper 004.html (12 April 2012).

10. Hunter GA. Chemical burns of the skin after contact with petrol. British Journal of Plastic Surgery 1968; 21: 373-341.

11. Anochie I, Graham-Douglas IB. Non-accidental Injuries Associated with Convulsions in Port Harcourt, Nigeria. Anil Aggrawal Internet Journal of Forensic Medicine and Toxicology 2000; 1(2): Available: http://www.anilaggrawal.com/ij/vol_001_no_ 002/paper009.html (12 April 2012).

12. Crisp AJ, Bhalla A K, Hoffbrand BI. Acute tubular necrosis after exposure to diesel oil. BMJ 1979; 2(6183): 177.

13. Udonwa NE, Ekpo M, Ekanem IA, Inem AV, Etokidem A. Oil boom and AIDS doom in the Niger Delta of Nigeria. Rural and Remote Health 4: 273. (Online) 2004. Available: www.rrh.org.au (Accessed 21 October 2011).

14. Araoye MO. Research methodology with statistics for health and social sciences. Ilorin: Nathandex, 2003.

15. Nxumalo N, Alaba O, Harris B, Chersich M, Goudge J. Utilization of traditional healers in South Africa and costs to patients: Findings from a national household survey. Journal of Public Health Policy 2011; 32: S124-S136.

16. Adibe MO. Prevalence of concurrent use of herbal and synthetic medicines among outpatients in a mission hospital in Nigeria. International Journal of Drug Development and Research 2009; 1: 60-66.
17. Tamuno I, Omole-Ohonsi A, Fadare J. Use of Herbal Medicine among Pregnant Women attending a Tertiary Hospital in Northern Nigeria. The Internet Journal of Gynecology and Obstetrics 2011; 15(2): Available: http://www.ispub.com/journal/the-internet-journalof-gynecology-and-obstetrics/volume-15-number-2/use-of-herbalmedicine-among-pregnant-women-attending-a-tertiary-hospital-innorthern-nigeria.html (12 April 2012).

18. Palinkas L A, Kabongo M L. The use of Complementary and Alternative Medicine by Primary Care Patients. Journal of Family Practice 2000; 49: 1121-1130.

19. Foster DA, Denning A, Wills G, Bolger M, McCarthy E. Herbal medicine use during pregnancy in a group of Australian women. BMC Pregnancy Childbirth 2006; 6: 21.

20. Astin JA. Why patients use alternative medicine: results of a national study. JAMA 1998; 279: 1548-1553.

21. Sreeramareddy CT, Shankar RP, Sreekumaran BV, Subba SH, Joshi HS, Ramachandran U. Care seeking behaviour for childhood illness- a questionnaire survey in western Nepal. BMC International Health and Human Rights 2006; 6(7): doi:10.1186/1472-698X-6-7.

22. Galabuzi C, Agea JG, Fungo BL, Kamoga RMN. Traditional Medicine as an Alternative Form of Health Care System: a Preliminary Case Study of Nangabo Sub-County, Central Uganda. African Journal of Traditional Complementary and Alternative Medicines 2010; 7(1): 11-16.

23. Galooba-Mutebi F, Tollman S. Shopping for health: affliction and response in a South African village. African Sociological Review 2007; 11(2): 64-79. 